\title{
CAMBRIDGE
}

\section{The Uncertain Reasoner's Companion}

\section{A Mathematical Perspective}

\section{J. B. PARIS}

Professor Paris provides here an introduction to the mathematical foundations of the subject. Ir is suited for readers with some knowledge of undergraduate mathematics but is otherwise self-contained, collecting together the key results on the subject, and formalizing within a unified framework the main contemporary approaches and assumptions.

f25.00 net HB $0521460891224 \mathrm{pp}$.

Cambridge Tracts in Theoretical Computer Science 39

\section{Metamathematics, Machines, and Gödel's Proof NATARAJAN SHANKAR}

The author describes the use of computer programs to check the proofs of several celebrated theorems in metamathematics, including those of Gödel and Church-Rosser. The computer verification using the Boyer-Moore theorem prover yields precise and rigorous proofs of these difficult theorems. It also demonstrates the range and power of automated proof checking technology.

f25.00 net HB $052142027 \times 248 \mathrm{pp}$.

Cambridge Tracts in Theoretical Computer Science 38

\section{Foundations of Parallel Computing}

\section{B. SKILLICORN}

This is the first comprehensive account of this new approach to the fundamentals of parallel programming. It presents a methodology for software construction that produces architectureindependent and intellectually abstract software.

f25.00 net HB $0521455111209 \mathrm{pp}$.

Cambridge International Series in Parallel Computation 7

\section{Mathematical Theory of Domains}

\section{STOLTENBERG-HANSEN, I. LINDSTRÖM and E. R. GRIFFOR}

This book is the first devored to providing an accessible, unified and self-contained introduction to domain theory. It can be, and has been, used as an introductory textbook or as a general reference for professionals in computer science and logic.

£30.00 net HB $0521383447 \quad 350$ pp.

Cambridge Tracts in Theoretical Computer Science 22

\section{Computational Geometry in C}

\section{JOSEPH O'ROURKE}

This is the first textbook suitable for introducing undergraduate students to the design of geometry algorithms. The self-contained treatment presumes only an elementary knowledge of mathematics, but reaches topics on the frontier of current research. Numerous exercises are provided at the end of every section.

f35.00 net HB $0521440343320 \mathrm{pp}$.

f16.95 net PB 0521445922

Cambridge books are available from good bookshops, alternatively ring UK + (44) (0)1223 325970 in the UK to order direct using your credit card, or fax us on UK + (44) (0) 1223 315052. For further information please email Giulia Williams on science@cup.cam.ac.uk 


\section{CAMBRIDGE}

\section{A Handbook of Categorical Algebra} FRANCIS BORCEUX

A Handbook of Categorical Algebra is designed to give a detailed account of what should be known by everybody working in, or using, category theory. As such it will be a unique reference. The three volumes are written in sequence, with the first being essentially selfcontained. There is ample material here for a graduate course in category theory, and the books should also serve as a reference for users.

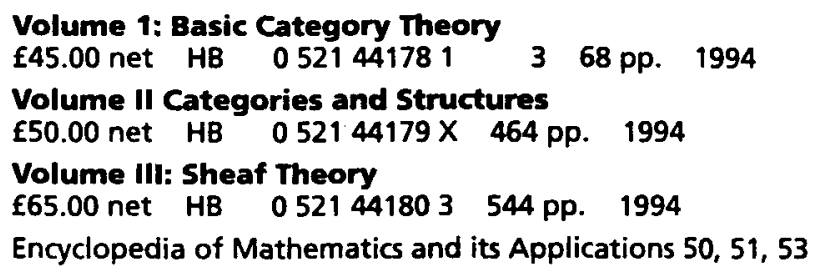

\section{First Steps in Modal Logic}

\section{SALLY POPKORN}

This is a first course in propositional modal logic written from a mathematical standpoint, essential for mathematicians, philosophers and computer scientists. The book covers all the basic material: propositional languages, semantics and correspondence results, proof systems and completeness results. There are many exercises, most with solutions. E25.00 net HB $052146482 \times \quad 328$ pp. 1994

\section{C by Example}

\section{NOEL KALICHARAN}

$C$ by Example assumes only familiarity with basic programming concepts such as variables and looping, but covers all aspects of the $\mathrm{C}$ language, including a detailed look at file handling and pointers. The text is self-contained and has a wealth of examples and exercises that test the understanding of the concepts developed in each chapter. Anybody who wishes to get to grips with the art of programming in $\mathrm{C}$ will find this a most valuable book.

$\begin{array}{llllll}\text { E35.00 net } & \text { HB } & 0521450233 & 378 \text { pp. } & 1994 \\ \text { E14.95 net } & \text { PB } & 0521456509 & & \end{array}$

Cambridge Computer Science Texts 29

Cambridge books are available from good bookshops, alternatively ring UK + (44) (0) 1223325970 in the UK to order direct using your credit card, or fax us on UK + (44) (0)1223 315052. For further information please email Giulia Williams on science@cup.cam.ac.uk
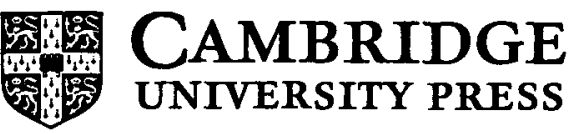

The Edinburgh Building, Cambridge CB2 2RU 


\section{INSTRUCTIONS TO AUTHORS}

SUBMISSION OF MANUSCRIPTS: Papers (three copies) may be submitted to any member of the Editorial Board. Authors should always keep a fully up-to-date version themselves. A copy of the paper and the name of the member of the Editorial Board to whom the paper has been submitted should also be sent to the Editor-in-Chief, who will record the submission. Submission of a paper is taken to imply that it has not been previously published and that it is not being considered for publication elsewhere. Upon acceptance of a paper, the author will be asked, under certain conditions, to transfer copyright to the publisher.

ELECTRONIC MANUSCRIPTS: The publisher encourages the submission of manuscripts written in LaTeX, which can be used for direct typesetting. Authors using LaTeX should use the MSCS style file, which can be obtained from the Editor-in-Chief or directly from the publisher using anonymous FTP to retrieve the file mscs. al 1 from the Internet address $f t p$. cup. cam . ac . uk where the macro is in the directory /pub/texarchive/journals/latex/mscs.all. The file mscs.all is a concatenated file containing both the style file and the author's guide; look at the readme header for information on how to split these files. In case of difficulties, there is a help-line available via e-mail, please contact texline@cup.cam.ac.uk. Alternatively, authors may use the 'article style'. The publisher may be able to use Plain TeX and AMSTeX for typesetting if submitted by authors. Authors should send discs (Apple Mac or PC) plus relevant details on acceptance of their paper to the Editor-in-Chief. The TeX (source code) files should be sent. These should correspond exactly to the hardcopy accepted for publication. Discs will not be returned. The publisher reserves the right to typeset any article by conventional means if the author's TeX code presents problems in production.

LAYOUT OF MANUSCRIPTS : Papers should be typewritten or equivalent in double spacing throughout, on one side of the paper. Please avoid footnotes. Papers should begin with an abstract of not more than 300 words.

FIGURES: Figures should be drawn in indian ink on good quality white paper or produced by computer to comparable quality. Wherever possible, they will be reproduced with the author's original lettering. Originals of figures should not be sent until the paper has been accepted. A list of captions should be attached separately.

REFERENCES: The Harvard system of references should be used. In the text, a reference should be quoted by the author's name and date in parentheses, in date order, e.g. (Smith 1983; Jones and Jones 1985; Hunter 1986a, b). Where there are three or more authors, the first name followed by $e t$ al. should be used. A full list of references should be given at the end of the text, listing, in alphabetical order, surname of author and initials; year of publication (in parentheses); title of paper; journal or book name (the former being abbreviated in accordance with the World List of Scientific Periodicals); volume number; first and last page of the reference. For books and conference proceedings, place of publication and publisher (and Editor(s) if appropriate) should be included.

PROOFREADING: As far as possible, changes at proof stage should be restricted to typographical errors, and the publisher reserves the right to charge the author for additional corrections.

OFFPRINTS : Twenty-five offprints of each article will be supplied free to each first named author. Extra offprints may be purchased from the publisher if ordered at proof stage.

\section{THE JOURNAL}

Mathematical Structures in Computer Science (MSCS) is a journal of theoretical computer science which focuses on the application of ideas from the structural side of mathematics and mathematical logic to computer science. The journal aims to bridge the gap between theoretical contributions and software design, publishing original papers or broad surveys with original perspectives in all areas of computing, provided that ideas or results from algebra, geometry or category theory form a basis for the work.

\section{EDITORIAL POLICY}

The purpose of the journal is to increase the circulation of new very high standard results in this fast growing area. Notions, methods and results from algebras, geometry and category theory nowadays play a major role in theoretical and even applied computer science. This role is increasing and is stimulating new research directions in these mathematical disciplines as well as influencing various aspects of actual computing. Indeed, this journal is not meant to be only a 'theory journal' but, by choosing as a theme the use of mathematical methods of Computer Science independently of their area of application, it aims to highlight connections among different topics and to encourage applications of theoretical contributions.

This journal welcomes original papers, or broad surveys with original perspectives. Their standard should be at least comparable to the quality of the best journal in computer science or in mathematics. The papers may be in any area of computing, provided that they employ concepts or results from category theory, algebra or geometry. The journal also welcomes applications to computing based on the use of specific mathematical structures (e.g. topological and order-theoretic structures) as well as on prooftheoretic notions and results. The use of categorical or algebraic language just as a unifying tool for a variety of applications is also appreciated, in particular if linked with relevant experimental activity. In order to promote the use of categorical methods in computer science, expository and introductory papers are particularly welcome, with the specific aim of turning the (sometimes excessively) technical jargon of the community of category theorists to a commonly understood language for as many working computer scientists as possible. Equally, discussions of methodological or philosophical nature concerning the foundation of Computer Science are of interest for the journal.

Articles in pure category theory or in other areas of mathematics may be considered provided that there is a clear connection to computational issues or they investigate mathematical structures whose relevance to computer science is well established. However, these contributions should be directed to the broad audience of computer scientists to which this journal is addressed, since the applications of mathematical methods in the broadest sense in language design and software implementation is meant to be the main focus of this journal. 


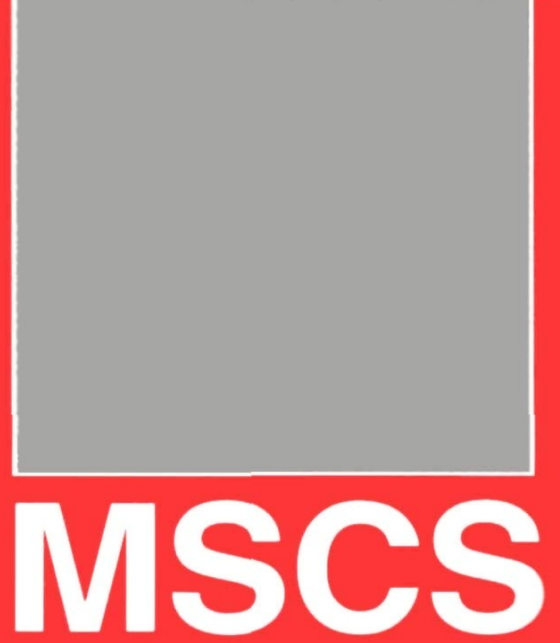

FEBRUARY 1996 VOLUME 6 NUMBER 1

\section{CONTENTS}

Datatype laws without signatures

MAARTEN M. FOKKINGA

Algebraic implementation of abstract data types: a survey of concepts and new compositionality results

FERNANDO OREJAS, MARISA NAVARRO AND ANA SANCHEZ

Constructive theory of the lower power locale

M. BUNGE AND J. FUNK

Non-strict don't care algebras and specifications

EGIDIO ASTESIANO AND MAURA CERIOLI

Cambridge University Press 1996

Printed in Great Britain by the University Press, Cambridge 